\title{
Performance of a Hybrid Wind-Grid-Load Energy System
}

\author{
Maamar Taleb, Hussain A. Salman, Hassan A. Jumaa and Hassan A. Al-Mukharreq \\ Department of Electrical and Electronics Engineering, University of Bahrain, P.O. Box 32038, ISA Town, \\ Bahrain
}

\begin{abstract}
A hybrid energy system consisting of a wind driven generator (WG) and a power utilities grid are interconnected. The hybrid energy system provides a constant power to an AC load regardless the surrounding weather conditions. The interconnection uses a controlled single phase full wave bridge rectifier. The bridge operates in the inverter mode of operation. This is done in purpose to guaranty the extraction of the real power from the wind driven generator. The extracted power is supplied to a constant AC load and any excess of power from the wind renewable energy source is injected into the power utility grid. At any pretended surrounding weather conditions, maximum extraction of power from the renewable energy source is targeted. This is done through the realization of a self-adjusted firing angle controller responsible of triggering the semiconductor elements of the controlled bridge rectifier. The performance of the proposed system has been simulated in MATLAB/SIMULINK environment and tested practically by building a laboratory prototype model. Quite satisfactory and encouraging results have been obtained.
\end{abstract}

Keywords: Integration of Renewable Energy Sources to Grid Systems, Wind Driven Generator, Maximum Power Point Trackers, MATLAB/SIMULINK Applications.

\section{INTRODUCTION}

With the increasing concerns about the global warming issue, renewable energy resources turn to be gaining more energy demand applications. Unfortunately, most (if not all) renewable energy resources suffer currently from the lack of providing constant power. This is due to the uncontrollable change in the surrounding weather and environmental conditions. A possible and practical solution to overcome the problem of not relying totally on the renewable energy resources, is to constitute a hybrid DC grid made of a combination of parallel energy resources and storage units and interconnect it (i.e the hybrid DC grid) to the AC grid [1-3]. The DC grid is connected to the AC grid through conventional power inverter modules [1-3]. A glance at the anticipated task from such proposed solution is that at any prospective energy load demand, the energy is guarantied from the DC grid as well as from the AC grid.

The present paper combines a wind driven generator (WG) with an available AC power utilities grid to form a hybrid energy system or hybrid energy supply. The overall hybrid energy supply is used to provide an $\mathrm{AC}$ load with a nearly constant power at any time of a day and regardless the surrounding weather conditions. The wind driven generator is presumably the main entity responsible of providing the constant power while the main AC supply is considered as a standby power source. Thus, the AC main supply

*Address corresponding to this author at the Department of Electrical and Electronics Engineering, University of Bahrain, P.O. Box 32038, ISA Town, Bahrain; Tel: +973 39151520; Fax: +973 17680924;

E-mail: maamar@eng.uob.bh

E-ISSN: 1929-6002/12 intervenes only when there is a real deficiency of energy from the WG energy source. No storage units are needed in the proposed hybrid energy system. The operation of the wind generator in the proposed energy system is controlled by a maximum power point tracker. That is to guaranty maximum extraction of power from the wind renewable energy source. The proposed method of interconnection eases the constraint of synchronization that is common imposed in the conventional interconnection of renewable energy resources with the $A C$ grid.

\section{STUDY SYSTEM}

A general scheme of the study system is represented in Figure 1a. The desired powers flow is simplified by the arrows direction. Figure $\mathbf{1 b}$ details further the circuit contents of Figure 1a. Figure 1b consists of three parts: a wind driven generator (WG) setup operated by a controlled single phase full wave bridge rectifier, an $\mathrm{AC}$ voltage source representing the power utilities side or the grid, and an AC power load. The full wave power bridge rectifiers is controlled by an external firing angle controllers. The polarities of the WG voltage source is reversed in the figure and that is to indicate that the WG will be generating power rather than absorbing power.

The next subsections describe the wind generator (WG) mathematical model and the contents of the important blocks of Figure 1.

\subsection{Wind Generator (WG) Model}

The wind driven generator setup consists of an ac generator connected in cascade with an uncontrolled 

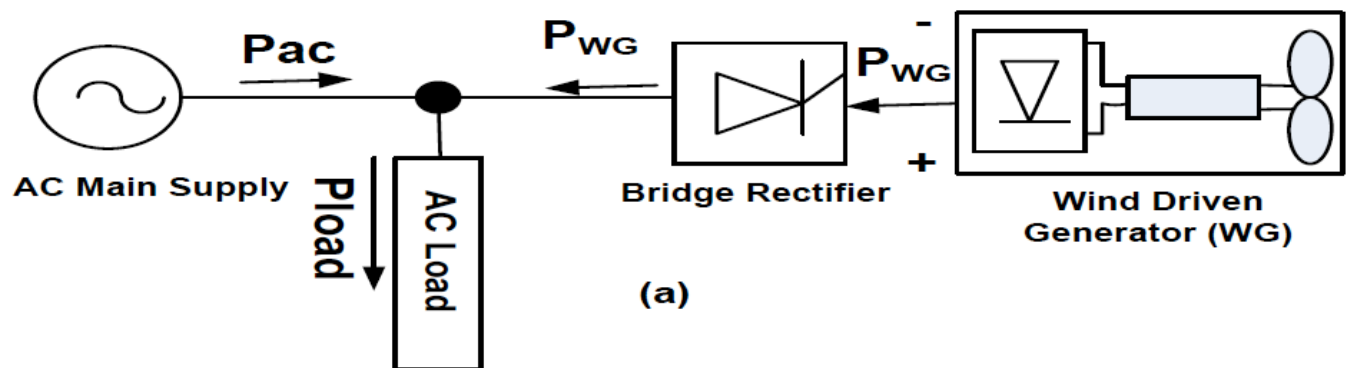

Generator (WG)

(a)

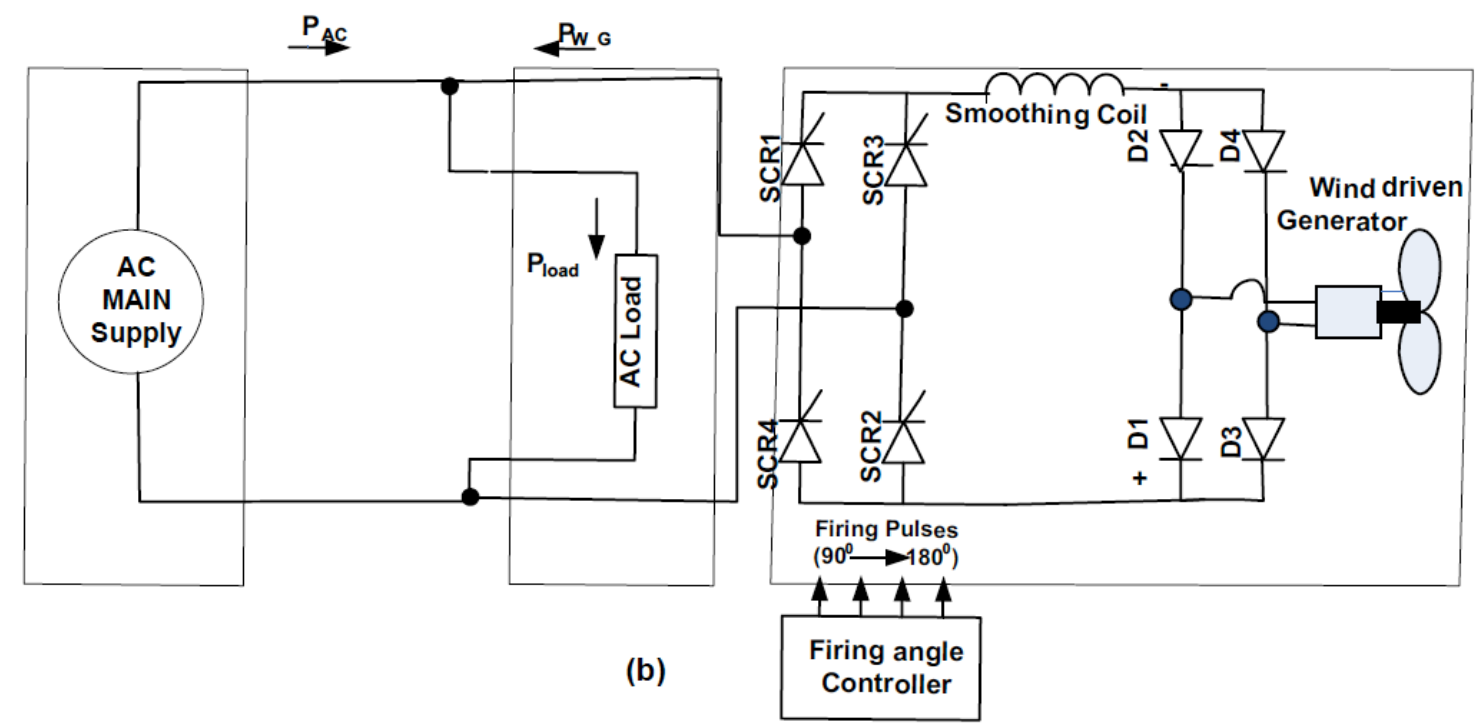

Figure 1: Study System a) One Line Diagram b) Single Phase Equivalent Circuit.

AC/DC single phase full wave bridge rectifier, and wind driven blades. The ac generator is made of a permanent magnet generator having stationary coil (stator) and rotor having a magnet assembly pole pieces forming two disc-shaped. Marlec company [4] is one of the worldwide famous companies that manufactures this type of wind generators. The AC generator can be modelled by an ac voltage source $\left(\mathbf{e}_{\mathrm{w}}\right)$ in series with resistance $\left(\mathbf{R}_{\mathrm{W}}\right)$ and inductance $\left(\mathbf{L}_{\mathrm{w}}\right)$. The level of the voltage generated by the ac voltage source is frequency dependent. The frequency depends in turns on the wind speed $\left(\mathbf{V}_{\mathbf{w}}\right)$.

Betz theory [5] can be used to estimate the power extracted from the wind power and supplied to the AC generator. The power of the moving air through a wind rotor can be expressed as [6]:

$P_{o}=\frac{1}{2} A_{r} \rho V_{w}^{3}$

$A_{\underline{r}}$ represents the swept area by the motor rotor and it is set to $A_{r}=\pi r^{2}$.

$\mathbf{r}$ represents the radius of the rotor. $\rho$ density of the air which may be taken at normal temperature and pressure as equals to $1.25 \mathrm{~kg} / \mathrm{m}^{3}$

$\mathbf{V}_{\mathbf{w}}$ is the wind speed in meter/second $(\mathrm{m} / \mathrm{s})$.

The moving air power $\left(P_{0}\right)$ can be converted partially to a mechanical power. The mechanical power that can be extracted from such moving air power can be expressed by [6]:

$P_{w}=C_{p} P_{o}$

$\mathbf{C}_{p}$ is a dimensionless performance power coefficient and its value is naturally always $<1$. Investigator of reference [6] proposed a handy formula for $\mathbf{C p}$ in the form of:

$C_{p}=C_{1}\left(C_{2}-C_{3} p-C_{4} p^{x}-C_{5}\right) e^{-C_{6}}$

Where $C_{1}=0.5, C_{2}=116 / \lambda_{i}, C_{3}=0.4, C_{4}=0 ., C_{5}=5$, $\mathrm{C}_{6}=21 / \lambda_{\mathrm{i}}, \mathrm{x}=1.5$.

$$
\frac{1}{\lambda_{i}}=\frac{1}{\lambda+0.08 p}-\frac{0.035}{p^{3}+1} \text { and } \lambda=\frac{r \omega_{w}}{V_{w}}
$$



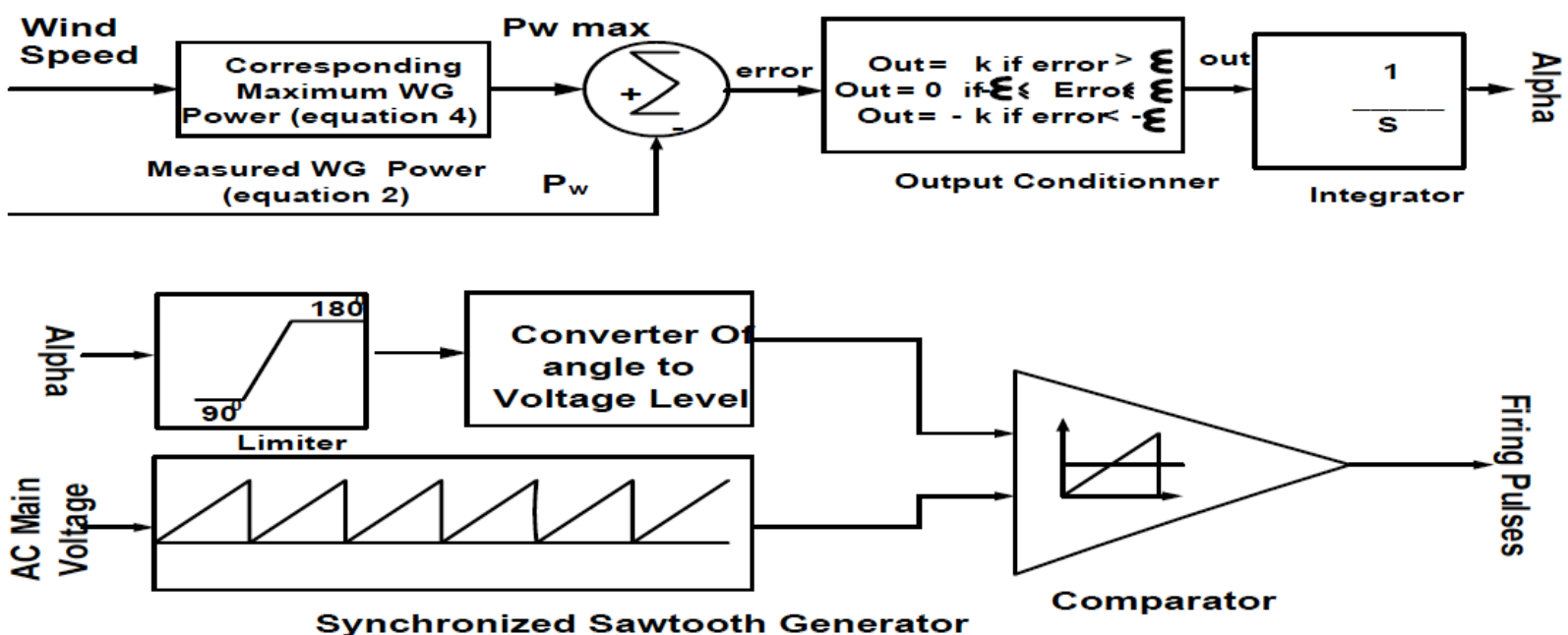

Figure 2: Firing angle Controllers Block.

p: pitch angle between the blade element with respect to the plane of rotation.

$\lambda$ is known as the tip speed ratio.

$\mathbf{C}_{\mathrm{p}}$ is maximized when the tip speed ratio $\lambda$ is equal to 7.975340822. The corresponding value of the coefficient $\mathbf{C}_{p}$ at such tip speed ratio is $\mathbf{C}_{p, \max }=$ 0.413814988 .

The maximum extracted power from the wind motor under such a condition is of the form:

$P_{w, \max }=\frac{1}{2} A_{r} \rho V_{w}^{3} C_{p, \max }=\frac{0.413814988}{2} A_{r} \rho V_{w}^{3}$

Thus, for the sake of extracting maximum wind power $\left(P_{\mathrm{w}, \max }\right)$ at a certain wind speed $\left(\mathrm{V}_{\mathrm{w}}\right)$, the wind motor speed has to be controlled by the firing angle controller block of Figure 1 and made the wind motor rotating at the following angular velocity:

$$
\omega_{w}=\frac{7.975340822 V_{w}}{r}
$$

\subsection{Power Bridge Controlled Rectifier}

The power bridge rectifier is no more than a controlled single phase full wave bridge rectifier. The rectifier is operated in a mode termed "Inverter Mode of Operation" [7]. In a such mode of operation, the firing angle provided to the SCRs valves of the bridge should be greater than $90^{\circ}$. The average value of the voltage at the dc side of the bridge rectifiers obeys the following expression:

$V_{D C}=K_{1} \cos (\alpha)$
$\mathrm{K}_{1}$ is a positive constant and it is proportional to the RMS value of the main AC supply voltage. Note that $\alpha$ represents the firing angle. For any value of the firing angle greater than $90^{\circ}$, the average voltage $V_{D C}$ is negative. A negative value of the voltage $V_{D C}$ times a positive value of the current that circulates in the smoothing reactor, results in a negative value for the power at the DC side of the controlled bridge rectifier. That leads to the statement that such power is generated by the WG renewable energy source and it is injected into the AC side of the bridge.

As to the way of generating or controlling the firing angle of the bridge rectifier, Figure 2 is suggested for the bridge rectifier carrying the WG setup.

The intended task from the firing angle controller of Figure $\mathbf{2}$ is to play the role of a maximum power point tracker and that is by being self-adjustable in guarantying a small steady state error between the maximum possible power of the WG source (i.e $P_{w, \max }$ of equation 4) and the power that is calculated on-line and generated by the voltage source of the WG source. Under such condition, the maximum power is extracted from the wind motor and the wind generator is guarantied to be rotating at the speed stated by equation (5).

\section{SYSTEM PERFORMANCE}

The performance of the proposed technique has been evaluated using computer simulations first then by assembling a prototype model in the laboratory. The performance looked for, in the two cases, consists of measuring continuously the power consumed by the AC load, the power delivered by the wind generator 
Table 1: System Data

\begin{tabular}{|c|c|c|c|}
\hline \multicolumn{2}{|c|}{ Wind Generator parameters } & \multicolumn{2}{c|}{ DC smoothing Coil Inductance $\mathbf{0 . 2} \mathbf{H}$} \\
\hline \hline $\mathrm{R}_{\mathrm{W}}$ & $6.5 \Omega$ & AC Voltage Source \\
\hline $\mathrm{L}_{\mathrm{w}}$ & $0.0484 \mathrm{H}$ & Voltage & $20 \mathrm{~V} \mathrm{rms} \mathrm{value}$ \\
\hline Blades length $(\mathrm{r})$ & $60 \mathrm{~cm}$ & Frequency & $50 \mathrm{~Hz}$ \\
\hline & $e_{w}=\frac{\sqrt{2}}{\pi} \frac{\lambda V_{W}}{r} \sin \left(\frac{\lambda V_{W}}{r} t\right)$ & Leakage Inductance & $5 \mathrm{mH}$ \\
\end{tabular}

AC load: Pure Resistance $20 \Omega$.

(WG), and the power delivered or absorbed by the AC voltage supply. The system data used in the simulations as well as in the practical part are provided in Table 1.

MATLAB/SIMULINK has been used in the computer simulations. Figure 3 visualizes the results obtained under certain pretended wind speed levels.

The previous results are the outputs of a SIMULINK file developed by the authors of this paper. The layout or the block diagram of the developed file is not provided in this paper due to the paper pages limitation constraint. However, the full developed SIMULINK file can be obtained by contacting the first author of the paper.

A careful examination of Figure 3, the following remarks can be noted:

- $\quad$ The AC load power stays constant (around 20 W) regardless the pretended wind speed levels.
- As the wind speed increases, more power contribution from the wind generator is noted and less power contribution from the AC voltage is needed.

Table 2 depicts the steady state values of the powers recorded at the different stages of the developed SIMULINK file. A glance at the sixth and the seventh columns of Table 2 , one can clearly notice that nearly maximum power is extracted from the wind generator at any pretended wind speed level. Thus, it can be said the firing angle controller of Figure 1 is performing the role of the maximum power point tracker. The tracker keeps updating automatically its firing angle value as the wind speed changes (as shown in the eight column of Table 2). The difference between the extracted power from the wind generator (i.e column 7 powers) and the power generated at the terminals of the wind generator (i.e column 5 powers) consists of the losses in the wind generator internal resistance $\left(R_{W}\right)$.

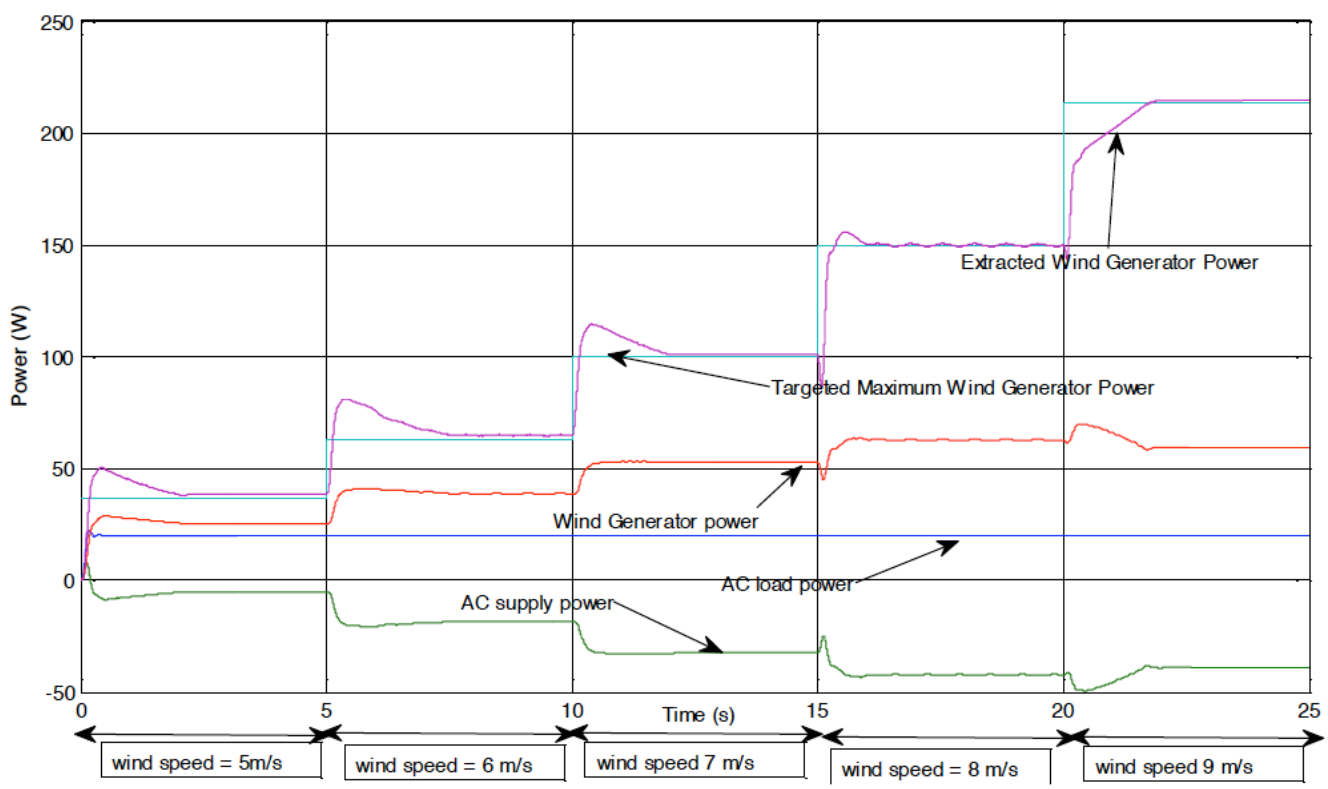

Figure 3: Computer Simulation Results: Power contributions. 
Table 2: Computer Simulations Steady State Results

\begin{tabular}{|c|c|c|c|c|c|c|c|}
\hline $\begin{array}{c}\text { Wind } \\
\text { Speed } \\
\mathbf{V}_{\mathrm{W}}(\mathbf{m} / \mathbf{s})\end{array}$ & $\begin{array}{c}\text { Wind Motor } \\
\text { Speed (rpm) }\end{array}$ & $\begin{array}{c}\text { AC Load } \\
\text { Power } \\
\mathbf{( W )}\end{array}$ & $\begin{array}{c}\text { AC source } \\
\text { Power } \\
\mathbf{( W )}\end{array}$ & $\begin{array}{c}\text { Wind } \\
\text { Generator } \\
\text { Terminals } \\
\text { Power (W) }\end{array}$ & $\begin{array}{c}\text { Extracted Power from the } \\
\text { Wind Generator } \\
\text { (i.e Wind Internal Voltage } \\
\text { Source Power) (W) }\end{array}$ & $\begin{array}{c}\text { Targeted } \\
\text { Maximum } \\
\text { Wind } \\
\text { Generator } \\
\text { Power (W) }\end{array}$ & $\begin{array}{c}\text { Corresponding } \\
\text { Firing angle } \\
\text { (degree) }\end{array}$ \\
\hline \hline 5 & 66.4612 & 19.999 & -5.388 & 25.3886 & 36.5450 & 38.3408 & 159.433 \\
\hline 6 & 79.7534 & 19.999 & -18.461 & 38.4613 & 63.1498 & 64.4882 & 166.9262 \\
\hline 7 & 93.0456 & 19.999 & -32.576 & 52.5756 & 100.2796 & 101.0944 & 158.9950 \\
\hline 8 & 106.3379 & 19.999 & -42.706 & 62.7056 & 149.6885 & 150.4174 & 142.1763 \\
\hline 9 & 119.6301 & 19.999 & -39.134 & 59.1338 & 213.1307 & 214.3807 & 120.0138 \\
\hline
\end{tabular}

As to the practical implementation of the proposed technique, the firing angle controller was built using a programmable microcontroller. The microcontroller requires at its input side a square waveform that should be in synchronism with the $A C$ voltage source (i.e grid supply) and a desired firing angle entered by the operator. The microcontroller delivers trains of pulses on two separate output ports. The train of pulses on the two outputs ports are delayed from each other by half period. Naturally, the train of pulses are supplied to the gates of the controlled bridge rectifier SCRs through interfacing circuits.

The wind speed has been represented by an three phase induction motor fed by a three phase supply. By fixing the firing angle at certain value and varying the wind driven generator at certain speeds, the read powers on the different wattmeters of the experimental are recorded and reported in Table $\mathbf{3}$.

Figure 4 visualizes behaviors of the recorded powers versus the wind motor speed at two firing angle values.
When analyzing the recorded measurements, the following remarks can be noted:

- $\quad$ The AC load power has stayed nearly constant regardless the prime motor speed and the firing angle values.

- As the motor speed is increased, more power contribution is observed from the wind generator side and less power is needed from the AC supply side.

- At any fixed wind speed motor, the increase of firing angle value resulted in more power extraction from the wind generator side. Unfortunately, the additional extracted power from the wind generator did not ease the burden on the AC source from contributing less power to the AC load. This is quite observed when comparing the AC powers recorded in the third and seventh columns of Table 3 . In reality, the additional extracted power from the wind generator has been partially consumed by the resistance of the smoothing coil in the DC link.

Table 3: Experimental Recorded Measurements

\begin{tabular}{|c|c|c|c|c|c|c|c|}
\hline \multicolumn{4}{|c|}{ When the firing angle is set to $110^{\circ}$} & \multicolumn{4}{|c|}{ When the firing angle is set to $120^{\circ}$} \\
\hline $\begin{array}{l}\text { Wind Motor } \\
\text { Speed } \\
\text { (rpm) }\end{array}$ & $\begin{array}{l}\text { AC Load } \\
\text { Power } \\
\text { (W) }\end{array}$ & $\begin{array}{l}\text { AC source } \\
\text { Power } \\
\text { (W) }\end{array}$ & $\begin{array}{l}\text { Wind Generator } \\
\text { Terminals Power } \\
\text { (W) }\end{array}$ & $\begin{array}{l}\text { Wind Motor } \\
\text { Speed } \\
(\mathrm{rpm})\end{array}$ & $\begin{array}{l}\text { AC Load } \\
\text { Power } \\
\text { (W) }\end{array}$ & $\begin{array}{l}\text { AC source } \\
\text { Power } \\
\text { (W) }\end{array}$ & $\begin{array}{c}\text { Wind Generator } \\
\text { Terminals } \\
\text { Power }(\mathrm{W})\end{array}$ \\
\hline 100 & 20.64 & 20.50 & 0.39 & & & & \\
\hline 200 & 20.73 & 19.20 & 2.09 & & & & \\
\hline 300 & 21.10 & 16.61 & 6.87 & 300 & 21.08 & 18.09 & 10.89 \\
\hline 380 & 21.05 & 13.00 & 13.16 & & & & \\
\hline 500 & 21.74 & 7.89 & 25.75 & 500 & 21.32 & 12.83 & 34.37 \\
\hline 550 & 21.87 & 4.41 & 34.02 & & & & \\
\hline 600 & 21.92 & 1.21 & 44.44 & 600 & 21.32 & 8.72 & 52.91 \\
\hline 800 & 22.09 & -3.63 & 64.74 & 800 & 21.55 & 1.61 & 93.93 \\
\hline
\end{tabular}




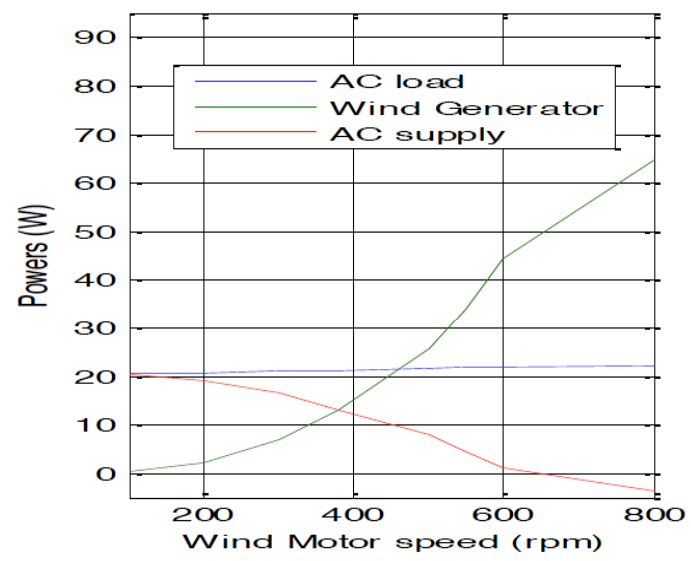

a)

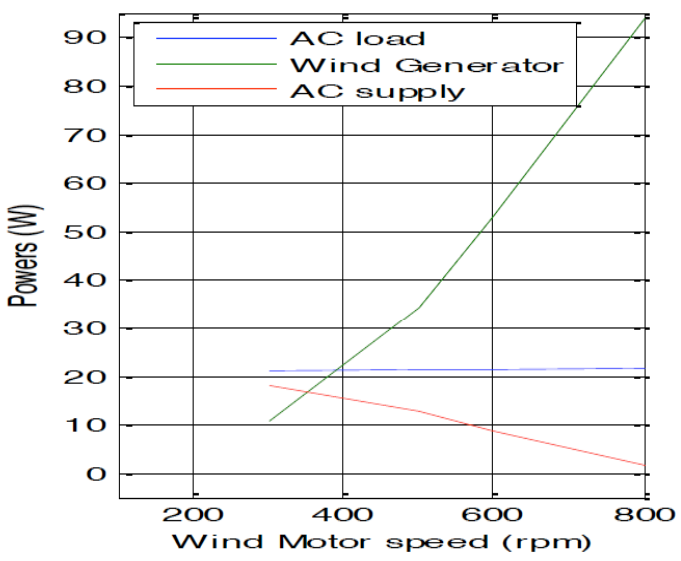

b)

Figure 4: Laboratory Model Recorded Powers a) when the firing angle is $110^{\circ} \mathbf{b}$ ) when the firing angle is $120^{\circ}$.

Increasing the firing angle resulted in an increase in the current of the smoothing coil and consequently there was additional heat losses in the resistance of the coil. The wind genertaor covered such additional heat losses. Therefore, the extracted power from the wind generator has not been totally injected into the AC side (i.e AC source side). The last behavior resulted in forcing the AC source to supply any deficiency in the power needed by the AC loabed. To overcome the last undesired behavior, a better quality factor smoothing coil inductor should be suggested.

\section{CONCLUSION}

Interconnecting a wind driven generator (WG) with an AC supply to feed an AC load with a nearly constant power has been investigated in this paper. The interconnection of wind driven generator has been done through the installation of controlled single full wave bridge rectifier operating in inverter mode of operation. The proposed technique offers certain merits like: no worries about the synchronization of the AC grid with the wind generator and no need for storage units.

The performance of the interconnection has been tested through computer simulations (using MATLAB/ SIMULINK computing tool) as well as through building or assembling a laboratory model. In the computer simulations, a maximum power is nearly extracted from the wind driven generator under certain pretended wind speed levels. In the practical part, the AC supply has been found to be flexible in generating the remaining needed power or absorbing the excess of energy between the power generated by the energy system and the required $\mathrm{AC}$ load power.

Unfortunately, the proposed technique came up with certain disadvantages like lowering the power factor and injecting distorted current signals into the grid.

\section{REFERENCES}

[1] Chedid R, Akiki H, Rahman S. A Decision Support Technique for the Design of Hybrid Solar-Wind Power Systems. IEEE Trans Energy Conver 1998; 13: 76-83. http://dx.doi.org/10.1109/60.658207

[2] Biczel P, Koniak M. Design of Power Plant Capacity in DC Hybrid System and Microgrid, Proceedings of the Fourth International Conference On Ecological Vehicles and Renewable Energies (EVER09), Monte Carlo, Monaco, March 26-29, 2009.

[3] IEEE Standard for Interconnecting Distributed Resources with Electric Power Systems. Standard IEEE 1547-2003, 2003.

[4] The Rutland 913 Windcharger, http://www.windandsun.co.uk/ Wind/wind_marlec.htm, Accessed January 05, 2012.

[5] Le Gourieres D. Wind Power Plants: Theory and Design, (in French), Paris. Eyrolles Company, 1982.

[6] Heier S. Grid Integration of Wind Energy Conversion Systems, New York, John Wiley and Sons Company 1998.

[7] Mohan N, Undeland TM, Robbins WP. Power Electronics: Converter, Applications, and Design, New Jersey, John Wiley and Sons Inc., 2003. 